\section{O QUE SE COMPREENDE POR GESTÃO SECRETARIAL: PERCEPÇÃO DE UMA AMOSTRA DE DISCENTES DE SECRETARIADO EXECUTIVO}

\section{RESUMO}

A Gestão Secretarial é um tema recorrente, porém sua delimitação ainda carece de estudos que a comprove como construto. $\mathrm{O}$ objetivo deste artigo é analisar a compreensão de uma amostra de discentes de Secretariado Executivo da Universidade Federal do Ceará acerca da Gestão Secretarial. Para sua consecução, foi realizada uma revisão de literatura seguida de uma pesquisa de campo com discentes regularmente matriculados na disciplina Técnicas de Secretariado II do Curso de Secretariado Executivo da Universidade Federal do Ceará (UFC). Participaram 53 estudantes de nível de graduação entre os anos de 2014 e 2015. Trata-se de um estudo descritivo e exploratório de natureza qualitativa cujos dados foram analisados por meio de análise de conteúdo e permitiram inferir que, entre os discentes participantes, há compreensão diversificada acerca da gestão secretarial, evidenciando uma ausência de conceito uniforme, porém com uma clara tendência para teorias de gestão sejam elas relacionadas diretamente às atividades secretariais ou de forma generalista. Percebeu-se que uma parte das respostas relaciona o assunto às práticas administrativas e não especificamente ao fazer secretarial.

Palavras-chave: Gestão secretarial. Percepção. Discentes de Secretariado.

\section{INTRODUÇÃO}

A área do Secretariado Executivo passou por mudanças significativas, especialmente nos últimos trintas anos, com a regulamentação da profissão em nível superior (BRASIL, 1985). A mudança do perfil profissional é fato, pois, se antes esteve calcado unicamente na técnica, atualmente recai sobre ele também uma postura gestora.

A alteração do perfil do secretário executivo tem sido amplamente explorada pela literatura (SCHMIDT et al., 2008; MOURA, 2008; GRANDO; CORREA; RINALDI, 2007; BORTOLOTTO; WILLERS, 2005; LOTTE, 2005) e diversos papéis têm sido atribuídos aos secretários, tais como: o assessor, proposto por Nonato Júnior (2009); os gerenciais (mentor, facilitador, monitor, 
coordenador, diretor, produtor, negociador e inovador) asseverados por Barros et al. (2013) e Barros, Silva e Ferreira (2015) e os Middle Mangager (defensor, sintetizador, facilitador e implementador) de Moreira et al. (2016). Tais propostas surgem a partir da compreensão que há uma mudança do fazer secretarial e, portanto, merecem e carecem de investigações que possibilitem o aprofundamento das discussões.

Os princípios de Administração e a transformação do POCCC (planejamento, organização, controle, coordenação e comando) de Fayol em PODC (planejamento, organização, direção e controle) tiveram desdobramentos nos últimos anos, e a gestão assumiu direcionamentos com enfoques para áreas diversas. Entre elas, o Secretariado Executivo com a proposição de uma atuação gerencial no campo desses profissionais.

A Gestão Secretarial, como parte do atual contexto de atuação dos secretários, tem sido submetida a diferentes perspectivas, e múltiplos assuntos são tratados como temas próprios: gestão de carreira (MACHADO, 2009), gestão de projetos (SILVA, 2011), tecnologia da informação (RESTIER, 2013), atendimento ao cliente (BRÜNE; GONTARECK, 2013), entre outros. A literatura aponta caminhos teóricos, mas ainda há uma lacuna expressiva de comprovação empírica de tais percursos. É preciso investigar e explorar a realidade prática da Gestão Secretarial. Tal cenário emana a carência de se identificar o que diversos atores da área entendem por gestão secretarial.

Embora seja oficialmente conteúdo de formação específica, foram encontrados poucos trabalhos científicos que debatem a delimitação da Gestão Secretarial, e não foram encontrados estudos que abordem o tema sob o enfoque aqui apresentado nem tampouco valendo-se da metodologia ora utilizada.

Diante do exposto e das lacunas apresentadas, este artigo visa responder ao seguinte questionamento: como uma amostra de discentes de Secretariado Executivo da Universidade Federal do Ceará compreende a Gestão Secretarial?
A pesquisa se justifica inicialmente pela importância do tema para a área, principalmente pela possibilidade de contribuição para seu desenvolvimento teórico. Ademais, existem lacunas a serem preenchidas, que, embora este estudo não se proponha a preencher todas, pretende contribuir para a ampliação acerca do temário proposto.

Investigar a visão dos discentes é meritório, pois estão sendo preparados para atuar como secretários executivos. Suas respostas emanam não só sua visão a respeito de uma proposta teórica que impactará em sua atuação, como explicita o conhecimento que têm a respeito do tema. Contribui também de forma empírica para o desenvolvimento do construto.

Sendo assim, o objetivo deste artigo é analisar a compreensão de uma amostra de discentes de Secretariado Executivo da Universidade Federal do Ceará acerca da Gestão Secretarial.

Este artigo está dividido em cinco seções incluindo esta introdução. O referencial teórico aborda a dificuldade dimensional da Gestão Secretarial e a relação da gestão na atuação do profissional de Secretariado. Em seguida, são apresentados os procedimentos metodológicos na terceira seção. A quarta seção apresenta os resultados e as discussões a partir dos dados da pesquisa de campo e suas análises. A quinta seção traz as considerações finais seguida das referências utilizadas na fundamentação deste trabalho.

\section{REVISÃO DE LITERATURA}

A literatura base revisada para fundamentação deste trabalho encontra-se organizada mediante a exploração de aspectos-chave para a compreensão das análises e discussões. A necessidade de se trabalhar esses conceitos proporciona uma maior maturidade para as bases teóricas e conhecimento importantes no âmbito acadêmico.

\subsection{GESTÃO SECRETARIAL: DIFI- CULDADE DIMENSIONAL}

A Gestão Secretarial é uma proposta que, embora bastante abordada, demanda es- 
tudos que a conduzam a uma delimitação teórica. Seu primeiro entrave reside na ausência de um conceito ou conceitos que a comporte. Acredita-se que esse desalinho é fruto da insipiente compreensão do que realmente é englobado pelo tema.

Os assuntos associados à Gestão Secretarial são variados, tais como: gestão de pessoas, virtualidade, gestão de carreira, gestão do tempo, tecnologia da informação, idiomas, consultoria, gerenciamento de rotina, empowerment, liderança, administração eclesiástica, gestão da qualidade, gestão do conhecimento, cidadania organizacional, entre outros.

Prevista como conteúdo específico para os cursos de Bacharelado em Secretariado Executivo (BRASIL, 2005), a Gestão Secretarial é um dos objetos de conhecimento do componente específico do Exame Nacional de Desempenho dos Estudantes (ENADE), abrangendo: empreendedorismo, processo de negociação, assessoria executiva, gestão da informação, organização de eventos e consultoria na área secretarial (BRASIL, 2011). Segundo Bíscolí e Cielo (2004), a disciplina de Gestão Secretarial fornece uma visão abrangente não só do mercado de trabalho, mas também da atuação do próprio profissional.

Sobre uma possível delimitação acerca da Gestão Secretarial, Barros et al. (2013) consideram que a discussão perpassa estudos sobre gerenciamento, bem como as competências gerenciais necessárias a sua atuação por englobar conhecimentos ecléticos, tanto de estrutura quanto de comportamento organizacional. $\mathrm{Na}$ percepção de Nonato Júnior (2012), a gestão secretarial é uma das áreas secretariais. Para Silva, Barros e Barbosa (2012), a Gestão Secretarial é uma assunto atual como uma leitura diferente das atividades do profissional de Secretariado Executivo.

Ressalte-se a intrínseca relação do tema com as mudanças organizacionais (BARROS; BRAGA; SILVA, 2011; BÍSCOLI; CIELO, 2004). Para pesquisadores da área, a Gestão Secretarial é fruto de um contexto social e organizacional cada vez mais exigente e dinâmico
(BARROS; BRAGA; SILVA, 2011). Diante de tal realidade, o perfil do profissional secretário se altera e amadurece, emergindo, assim, atribuições e papéis que requerem competências gerenciais (BARROS et al., 2013; MOREIRA et al., 2016).

Percebe-se, portanto, o amplo e variado temário atribuído à Gestão Secretarial. Tal realidade é compreensível considerando que os múltiplos assuntos abordados são frutos de tentativas de demarcação do construto em questão por meio de pesquisas científicas. Porém, é lícito ressaltar que "[...] é desejo de toda ciência que seus preceitos sejam compreendidos e aceitos [...] o problema reside em popularizar o termo antes de comprovar a veracidade do mesmo" (ROBERTS et al. 2002, p. 77). Neste sentido, Guarido Filho, Machado-da-Silva e Gonçalves $(2009$, p. 1) asseveram que "A construção do conhecimento científico é um processo social caracterizado pela dinâmica recursiva entre as dimensões social e intelectual". Nestas condições, a Gestão Secretarial necessita de pesquisas que aprofundem sua dimensão conceitual e comprovação empírica.

\subsection{A GESTÃO E A ATUAÇÃO DO PROFISSIONAL DE SECRETARIADO EXECUTIVO}

Abordar a evolução do perfil profissional do secretário poderia soar redundante, haja vista sua ampla exploração na literatura específica (RIBEIRO, 2005; SABINO; ROCHA, 2004), porém faz-se necessário percorrer possibilidades de sua atuação.

Tal profissional, marcado historicamente por atividades eminentemente técnicas, depara-se com a possibilidade de atuação gerencial (EDDY; AKPAN, 2007), pois o secretário tem-se desenvolvido e evoluído a ponto de envolver atividades de gestão em seu cotidiano (BARROS et al., 2013).

Embora as atividades técnicas sejam necessárias ao desenvolvimento das atribuições secretariais, a profissão vem demonstrando constante avanço na abordagem dos conceitos 
da gestão (BECKER; CEOLIN, 2010). Esse cenário reposiciona o secretário para além da mera execução e o aloca como tomador de decisões (LASTA; DURANTE, 2008). "Ao secretário executivo, neste novo contexto, portanto, cabe, então, o papel de gestor nas organizações em que atua, estando, assim apto a perceber, refletir, decidir e agir de maneira assertiva" (BÍSCOLI; CIELO, 2004, p. 17) e gerir aspectos fundamentais como tecnologia, pessoas e informações (EDDY; AKPAN, 2007; AKPOMI; ORDU, 2009; HALICI; YILMAZ; KASIMOĞLU, 2012; RIZZI, 2013).

Entre as abordagens propostas como parte da Gestão Secretarial, há de se questionar sua efetividade na prática. Ribeiro (2005) já afirmava que a atuação do secretário adaptava-se aos paradigmas vigentes no cenário empresarial. $\mathrm{Na}$ esteira desse pensamento, Dias e Cardoso (2011) asseguram a aptdão do secretário para a atuação além da assessoria de um executivo, mas assumindo uma posição de gestor.

A gestão e consequentemente o perfil gerencial são evocados por diversos prismas, não sendo observados ainda seus limites no campo secretarial. Neste se observam algumas tentativas que são postas, como a assessoria, a gestão, a consultoria e o empreendedorismo, sendo as dimensões base para a atuação do secretário (SILVA, 2010). Essa demarcação é sustentada no entendimento da assessoria e da gestão como as dimensões que mais se aproximam e estão vinculadas à área secretarial (SILVA, 2013).

Sobre um possível limite para a gestão secretarial, Silva (2013) acrescenta que o trabalho do secretário deve colaborar com o processo de gestão da organização de forma ampla. Barros, Silva e Ferreira (2015) consideram que sua aplicabilidade ocorre nos serviços de secretaria, ou seja, a Gestão Secretarial é restrita ao fazer secretarial.

A abordagem da gestão no Secretariado Executivo e mais especificamente a Gestão secretarial como proposta teórica e prática são fecundas e há uma gama de possibilidades a ser explorada. Suas proposições teóricas, embora já encontrem algum amparo empírico, ainda carecem de aprofundamento. Percebe-se que há uma expectativa no que diz respeito à gestão no campo de atuação do secretário. É necessário, portanto, que se concheça se tal expectativa é inerente ao pensamento de toda a comunidade da área.

\section{METODOLOGIA}

Os procedimentos metodológicos adotados seguiram orientação da literatura citada para que fosse mantido o rigor que garante fidedignidade à pesquisa.

\subsection{TIPOLOGIA DA PESQUISA}

$\mathrm{O}$ presente estudo tem uma abordagem qualitativa, a qual, na visão de Godoi e Balsini (2010), é muito mais complexa do que apenas não usar números. Para os autores, a pesquisa qualitativa abrange várias formas de investigação e ajuda o pesquisador a compreender e explicar fenômenos sociais por meio da compreensão do comportamento de seus agentes e dos motivos que justificam suas ações (GODOI; BALSINI, 2010). Os dados qualitativos são, na realidade, representação dos atos e das intenções dos atores sociais.

Quantos aos fins, a pesquisa também se classifica como descritiva, porque expõe uma realidade sem procurar relações de causa e efeito, e exploratória, pois este tipo de pesquisa é feita, sobretudo, quando o tema escolhido é pouco explorado e "torna-se difícil formular hipóteses precisas e operacionalizáveis" (BEUREN, 2008, p. 80).

\subsection{SUJEITOS DA PESQUISA DE CAMPO, UNIVERSO E AMOSTRA}

A pesquisa de campo limita-se ao universo dos discentes regularmente ativos no Curso de Secretariado Executivo da Universidade Federal do Ceará (UFC) e foi realizada nos semestres 2014.1 e 2015.1 que possuíam o universo de 129 e 165 discentes ativos no curso, respectivamente. 
Participaram da pesquisa 53 discentes de graduação que cursavam a disciplina Técnicas de Secretariado II durante o período descrito, distribuídos em 24 discentes no período de 2014.1 e 29 discentes no período 2015.1. Conforme a integralização curricular do curso, a referida disciplina é ofertada anualmente no terceiro semestre.

Mesmo sendo possível delimitar numericamente o universo, considera-se a afirmativa de Triola (2012), que, em determinadas situações, o tamanho da população é irrelevante para determinação do tamanho da amostra. Diante do exposto, os critérios de definição da amostra, portanto, foram: ser discente de Secretariado Executivo da UFC, matriculado na disciplina de Técnicas de Secretariado II, no período de 2014.1 ou 2015.1 e acessibilidade, ou seja, pela concordância dos discentes em participar da pesquisa, já que a participação era voluntária.

A delimitação da amostra aos discentes matriculados no terceiro semestre do curso foi feita tomando por base o fato de o conteúdo de gestão secretarial ser discutido mais profundamente na disciplina Técnicas de Secretariado II ofertada neste período, embora outras disciplinas do curso sejam permeadas pelo tema desde o primeiro semestre. Considerou-se principalmente que, na referida disciplina, ocorre o maior debate sobre o assunto incluindo sua efetiva ocorrência na vida dos profissionais e sua proposta científica. Ademais, a proposta é que a pesquisa seja reaplicada com as mesmas turmas em outros momentos quando dados complementares forem coletados, transformando a pesquisa em longitudinal ao explicitar as transformações, ou não, do pensamento do alunato acerca do assunto.

\subsection{TÉCNICAS E INSTRUMENTO DE COLETA, TRATAMENTO E ANÁLISE DOS DADOS}

Para atingir o objetivo proposto, foi realizada, inicialmente, uma revisão de literatura seguida de uma pesquisa de campo cuja investigação se deu por meio do questionamento: "O que você compreende por Gestão Secretarial"? Após certificação de que todos os presentes na sala de aula possuíam algum tipo de conhecimento prévio sobre assunto, a indagação foi feita de forma oral, e cada aluno respondeu ao questionamento, conforme sua compreensão individual do tema, de forma anônima e por meio de narrativa escrita. Após a entrega das narrativas, ocorreu um debate acerca da proposta teórica e delimitação da Gestão Secretarial.

$\mathrm{O}$ questionamento foi realizado por um dos pesquisadores que interveio o mínimo possível no processo de resposta, dando apenas explicações quando solicitadas, mas evitando emitir significados diferentes daqueles atribuídos pelos respondentes. Cada respondente gastou em média 10 minutos para escrever.

As respostas coletadas na pesquisa foram digitadas e registradas em um banco de dados e interpretadas por meio de análise de conteúdo. Compreende-se a análise de conteúdo como um conjunto de técnicas de análise utilizado para a descrição de conteúdos de mensagens e comunicações, dividido em três fases: pré-análise, exploração do material e tratamento dos resultados, inferência e interpretação (BARDIN, 2002). Nesta fase, utilizou-se o Qualitative Solutions Research Nvivo 2.0 (QSR) para auxiliar a operação da análise das informações obtidas, considerando-se que o uso de software em pesquisa qualitativa torna o processo investigativo mais sistemático e livra o pesquisador de tarefas mecânicas. Além disso, permite a construção de padrões significativos dos fatos por meio de uma estrutura nos dados e desenvolvimento de tipologias descritivas e de teorias, bem como a análise detalhada do texto (KELLE, 2002).

Inicialmente, foi feita a organização do texto e inseriu-se no software Nvivo o projeto de pesquisa, os fichamentos, os textos e os artigos pesquisados utilizados no referencial teórico. Em seguida, realizou-se a seleção dos aspectos relevantes desse material para codificar os dados de acordo com os assuntos comuns existentes. Com o apoio do software fo- 
ram incluídas "[...] diferentes informações ou recortes de texto em diferentes categorias e ao mesmo tempo, quando pertinente, uma mesma informação em cateorias distintas" (GUIZZO; KRZIMINSKI; OLIVEIRA, 2003, p. 53). O sentido para a atividade de análise das informações foi dado pelas investigadoras as quais se debruçaram sobre o material a partir de um olhar à luz da teoria abordada, considerando-se que a interpretação dos dados deve ser sempre desenvolvida por um intérprete humano (KELLE, 2002). Nestas condições, os dados foram coletados, digitados, reunidos por aproximação de conteúdos das respostas, aglomerados por grupos e analisados com o auxílio do software Nvivo. As análises, inferências e interpretações são apresentadas a seguir.

\section{RESULTADOS}

Os dados apresentados a seguir estão dispostos de forma a facilitar a compreensão. O Quadro 1 apresenta as respostas coletadas na pesquisa de campo. As respostas foram sintetizadas sem prejuízo ao seu conteúdo. Em segui$\mathrm{da}$, foram reunidas em três grupos. O primeiro grupo, denominado "Gestão em Secretariado", engloba as respostas que relacionam gestão às atividades secretariais. O segundo grupo, denominado "Gestão organizacional", abrange as respostas que relacionam a gestão secretarial à gestão no âmbito das organizações. O terceiro grupo, identificado como "Outros", compreende atividades secretariais sem relacioná-las diretamente à gestão, além de respostas diversas.

\begin{tabular}{|c|c|c|}
\hline Gestão em Secretariado & Gestão organizacional & Outros \\
\hline $\begin{array}{l}\text { Secretária como gestora, um elo } \\
\text { organizacional. }\end{array}$ & Planejar, organizar e obter resultados. & Capacidade multifuncional. \\
\hline $\begin{array}{l}\text { Secretário passa da função de } \\
\text { assessor para gestor. }\end{array}$ & $\begin{array}{l}\text { Gerir informações com visão } \\
\text { sistêmica e demais competências }\end{array}$ & $\begin{array}{l}\begin{array}{l}\text { Início da autonomia da } \\
\text { secretária. }\end{array} \\
\end{array}$ \\
\hline $\begin{array}{l}\text { Gestão das atividades de um } \\
\text { secretário executivo. }\end{array}$ & $\begin{array}{l}\text { Gerenciamento de atividades } \\
\text { administrativas. }\end{array}$ & $\begin{array}{l}\text { Aborda pontos como } \\
\text { formação, atribuição, } \\
\text { conhecimento e desafios. }\end{array}$ \\
\hline Gestão dos processos secretariais. & $\begin{array}{l}\text { Competência de coordenar não só } \\
\text { as próprias atividades, mas também } \\
\text { buscar ajudar a organização, o } \\
\text { superior, influenciando e ajudando na } \\
\text { tomada de decisões. }\end{array}$ & $\begin{array}{l}\text { Conjunto de competências } \\
\text { oferecidas pelo assessor. }\end{array}$ \\
\hline Ser um gestor na área secretarial. & $\begin{array}{l}\text { Secretário atua como gestor, na } \\
\text { tomada de decisão e organização dos } \\
\text { processos. }\end{array}$ & $\begin{array}{l}\text { É a forma como o } \\
\text { secretário age, tomando } \\
\text { como base o papel do } \\
\text { assessor. }\end{array}$ \\
\hline $\begin{array}{l}\text { Gerir todas as competências } \\
\text { e atividades pertinentes ao } \\
\text { secretariado. }\end{array}$ & $\begin{array}{l}\text { Secretário atua na gestão dentro das } \\
\text { organizações. Aplicando suas visões, } \\
\text { percepções e conhecimentos. }\end{array}$ & $\begin{array}{l}\text { Desenvolvimento/ } \\
\text { acompanhamento das } \\
\text { técnicas secretariais. }\end{array}$ \\
\hline $\begin{array}{l}\text { Capacidade de gerir o que é } \\
\text { próprio do secretariado. }\end{array}$ & $\begin{array}{l}\text { Tornar-se gestor do ambiente } \\
\text { organizacional. }\end{array}$ & $\begin{array}{l}\text { É a arte de ser "a } \\
\text { executiva". }\end{array}$ \\
\hline $\begin{array}{l}\text { Habilidade que o secretário tem } \\
\text { de planejar, executar, controlar e } \\
\text { avaliar suas atividades. }\end{array}$ & $\begin{array}{l}\text { Administrar ou gerenciar negócios, } \\
\text { pessoas ou recursos. }\end{array}$ & $\begin{array}{l}\text { Rege as atividades do } \\
\text { secretário. }\end{array}$ \\
\hline $\begin{array}{l}\text { Ser gestor de seu campo de } \\
\text { atuação. }\end{array}$ & $\begin{array}{l}\text { Gestão e atribuição de gerir ou } \\
\text { administrar algo/alguém. }\end{array}$ & $\begin{array}{l}\text { É o secretário conseguir } \\
\text { executar o seu papel. }\end{array}$ \\
\hline $\begin{array}{l}\text { Administrar a rotina de trabalho do } \\
\text { secretário }\end{array}$ & $\begin{array}{l}\text { Política de valores que planeja, aloca } \\
\text { e gera recursos. }\end{array}$ & $\begin{array}{l}\text { É a maneira como o } \\
\text { profissional de secretariado } \\
\text { exerce as suas atribuições. }\end{array}$ \\
\hline
\end{tabular}




\begin{tabular}{|c|c|c|}
\hline $\begin{array}{l}\text { Gerenciar a forma de secretariar } \\
\text { gestores }\end{array}$ & $\begin{array}{l}\text { Técnicas e práticas de gerenciar } \\
\text { pessoas, recursos e tempo }\end{array}$ & $\begin{array}{l}\text { As atividades do cargo do } \\
\text { secretário. }\end{array}$ \\
\hline $\begin{array}{l}\text { Administração dos processos que } \\
\text { fazem parte das atividades do } \\
\text { secretário }\end{array}$ & $\begin{array}{l}\text { Administrar de forma eficaz e com } \\
\text { eficiência os processos para gerir } \\
\text { resultados positivos. }\end{array}$ & Engloba o fazer secretarial \\
\hline $\begin{array}{l}\text { O secretário planeja, organiza, } \\
\text { desenvolve e finaliza. }\end{array}$ & $\begin{array}{l}\text { Maneira de lidar com todos os } \\
\text { problemas e soluções que surgem na } \\
\text { empresa. }\end{array}$ & \\
\hline $\begin{array}{l}\text { Visão e gerenciamento de todas as } \\
\text { atividades das secretárias em geral. }\end{array}$ & Atividades ligadas à gestão. & \\
\hline $\begin{array}{l}\text { Coordenação e organização das } \\
\text { atividades secretarial. }\end{array}$ & $\begin{array}{l}\text { Ações realizadas pelo secretário } \\
\text { executivo a fim de gerir processos, } \\
\text { recursos e pessoas. }\end{array}$ & \\
\hline $\begin{array}{l}\text { Administrar as funções e/ou } \\
\text { demandas do secretariado. }\end{array}$ & $\begin{array}{l}\text { Atividade promissora, com uma grande } \\
\text { abrangência de atividades, que necessita } \\
\text { da participação de forma ativa do } \\
\text { secretário para que essa gestão venha a } \\
\text { ser positiva para a organização, de forma } \\
\text { que a gestão venha ganhando espaço no } \\
\text { meio secretarial. }\end{array}$ & \\
\hline \multicolumn{3}{|l|}{$\begin{array}{l}\text { Gerir suas atividades com pro } \\
\text { atividade, eficiência, domínio, } \\
\text { segurança e liderança. }\end{array}$} \\
\hline \multicolumn{3}{|l|}{$\begin{array}{l}\text { Arte de gerenciar todo e qualquer } \\
\text { processo da função do secretário } \\
\text { executivo. }\end{array}$} \\
\hline \multicolumn{3}{|l|}{$\begin{array}{l}\text { Secretário acrescenta as suas } \\
\text { funções a tomada de decisão e } \\
\text { comando de equipe. }\end{array}$} \\
\hline \multicolumn{3}{|l|}{$\begin{array}{l}\text { Planeja, organiza, dirige e } \\
\text { controla as atividades do seu fazer } \\
\text { profissional. }\end{array}$} \\
\hline $\begin{array}{l}\text { Secretária fazer mais do que suas } \\
\text { atividades rotineiras. }\end{array}$ & & \\
\hline
\end{tabular}

Quadro 1- Respostas à pergunta “o que você compreende por Gestão Secretarial"?

Fonte: dados da pesquisa de campo $(2014,2015)$.

Observa-se que, na distribuição das respostas, a maioria das percepções dos discentes acerca da Gestão Secretarial estão relacionadas à gestão no fazer secretarial. Ressalta-se, ainda, a compreensão de que a Gestão Secretarial contribui para a gestão no âmbito organizacional.

No que diz respeito ao grupo "Gestão em Secretariado", que trata das respostas que relacionam gestão às atividades secretariais, foram dispostas as afirmativas cujos conteúdos se aproximavam de tal relação. As respostas "O secretário planeja, organiza, desenvolve e fina- liza", "Administrar as funções e/ou demandas do Secretariado" e "Secretária fazer mais do que suas atividades rotineiras" evidenciam que o discente compartilha a visão de desenvolvimento da profissão, desvencilhando-a da mera executora, e a visão de Barros et al. (2013) acerca do caminhar profissional rumo às atividades de gestão.

A maioria das respostas do grupo "Gestão em Secretariado" aponta a Gestão Secretarial como sendo o gerenciamento das atividades secretariais. Para Silva, Barros e Barbosa (2012) representa uma leitura diferente das 
atividades do profissional de Secretariado Executivo. Assim, ser gestor de seu próprio papel nas organizações reflete esse novo olhar sobre sua atuação.

A compreensão dessa leitura diferente sobre o Secretariado Executivo não subtrai toda a conquista técnica da profissão, ao contrário, soma-se a ela. A diferenciação do momento vivido pelos secretários atualmente é o fato de serem agregadas às suas funções, atribuições mais complexas com possibilidade de tomada de decisão (LASTA; DURANTE, 2008) e atuação mais significativa no contexto organizacional. Essa realidade é evidenciada na resposta "Secretário acrescenta as suas funções a tomada de decisão e comando de equipe".

A diferenciação entre ser assessor e gestor fica clara na afirmativa "Secretário passa da função de assessor para gestor". Vale ressaltar que os papéis atribuídos aos secretários (BARROS et al., 2013; NONATO JÚNIOR, 2009) ainda carecem de aprofundamentos tanto na dimensão social como intelectual necessárias na pesquisa científica (GUARIDO FILHO; MACHADO-DA-SILVA; GONÇALVES, 2009).

A observação das respostas inseridas no gupo "Gestão organizacional" denota que a Gestão Secretarial é compreendida pelos discentes como uma atuação desenvolvida por meio das funções gerenciais. Essa perspectiva pode ser percebida com base em respostas como: "Planejar, organizar e obter resultados". Ressalte-se ainda a ênfase dada às competências, por meio das afirmações: "Gerir informações com visão sistêmica e demais competências", "Conjunto de competências que gerenciam as atividades do secretario" e "Conjunto de competências oferecidas pelo assessor". Tais competências são necessárias principalmente porque a Gestão Secretarial é fruto do dinamismo social e organizacional (BARROS; BRAGA; SILVA, 2011; BÍSCOLI; CIELO, 2004) e das exigências que recaem sobre os profissionais sob pena de se tornarem obsoletos. É determinante que os discentes tenham esta capacidade de compreensão.

Os discentes fazem uma relação entre as atividades secretariais e a gestão ao consi- derarem que a Gestão Secretarial envolve "atividades ligadas à gestão" e "gerenciamento de atividades administrativas". Nessa linha de pensamento, destaca-se que o secretário executivo, por ser um facilitador da obtenção de resultados, deve desenvolver o processo administrativo em seu campo de atuação (BARROS; SILVA; FERREIRA, 2015).

Os conceitos de gestão destacados Becker e Ceolin (2010) se tornam evidentes em diversas respostas e pode-se afirmar que norteiam diversas respostas, como: "Planejar, organizar e obter resultados", "Gerenciamento de atividades administrativas" e "Administrar de forma eficaz e com eficiência os processos para gerir resultados positivos".

Ressalta-se o impacto das adividades de Gestão Secretarial para a organização como um todo, visto que os discentes denotaram as seguintes compreensões: "tornar-se gestor do ambiente organizacional", "atividade promissora, com uma grande abrangência de atividades, que necessita da participação de forma ativa do secretário para que essa gestão venha ser positiva para a organização, de forma que a gestão vem ganhando espaço no meio secretarial". "Maneira de lidar com todos os problemas e soluções que surgem na empresa". Na esteira desse pensamento, Barros, Silva e Fereira (2015) ponderam que a amplitude das responsabilidades do gestor secretarial abrange a área de atuação específica de Secretariado cujas atividades são refletidas na organização como um todo.

Os dados refletem também os conhecimentos ecléticos e de visão abrangente defendidos por Barros et al. (2013) e Bíscolí e Cielo (2004). Ao observar-se o grupo "Outros", verifica-se que há uma concepção da Gestão secretarial como o fazer Secretariado em si, ou seja, de que a Gestão Secretarial é a própria atividade do secretário. Tal percepção é compreensível considerando o pensamento de Silva (2013) de que a assessoria e a gestão são as dimensões que mais se aproximam e estão vinculadas à área, bem como o pensamento de Nonato Júnior (2012) de que a Gestão Secretarial é uma das áreas do Secretariado. 
Embora a Gestão Secretarial não seja o fazer Secretariado em si, ao ser apontada como tal, mostra que o estudante relaciona-a diretamente à prática profissional. Essa relação é salutar, pois, mesmo sem um conceito ou delimitação definidos, há uma percepção da Gestão Secretarial como algo que diz respeito ao cotidiano profissional e não apenas uma proposta restrita ao cenário acadêmico.

As respostas "Rege as atividades do secretário", "É a maneira como o profissional de secretariado exerce as suas atribuições" e "engloba o fazer secretarial", encontram amparo na assertiva de Silva, Barros e Barbosa (2012, p. 109) de que "A Gestão Secretarial faz-se presente nos assuntos atuais como sendo uma leitura diferente das atividades do profissional de Secretariado Executivo". Justifica-se, assim, a leitura diferenciada que possivelmente o discente tem de sua futura atuação.

Destaquem-se também respostas que enfatizam ainda o trabalho especificamente técnico do secretário. De maneira geral, o grupo "Outros" apresenta respostas aproximadas em termos de conteúdos sem destaque para nenhuma resposta como especificamente distante em termos de concepção ou relação acerca do secretariado executivo ou dos conceitos de gestão.

As respostas apresentadas, em termos gerais, permitem o vislumbre de clara indefinição, entre os discentes, sobre o que representa, especificamente, a Gestão Secretarial para eles. A variedade de respostas acena ausência de consenso e pode ser resultante da própria carência de delimitação do construto. Como observado na revisão de literatura, o temário envolvendo a Gestão Secretarial é amplo e, portanto, é possível que as respostas coletadas sejam reflexos de tal realidade.

Por outro lado, embora haja percepções diferentes, a pesquisa aponta para uma possível delimitação da Gestão Secretarial em dois âmbitos. $\mathrm{O}$ primeiro diz respeito à gestão na área específica do Secretariado. O segundo aborda contribuições da atuação secretarial para a gestão da organização, corroborando Barros, Silva e Ferreira (2015), ao afirmarem que as ativida- des, a abrangência e as competências do secretário denotam desafios a serem superados tendo em vista uma atuação capaz de colaborar para o alcance de metas e objetivos organizacionais. Infere-se, portanto, que os discentes possuem visão pautada nas teorias de gestão e não difere do que é apontado pela literatura.

\section{CONCLUSÕES}

O presente estudo buscou analisar a compreensão de uma amostra de discentes de Secretariado Executivo da Universidade Federal do Ceará acerca da Gestão Secretarial. A revisão de literatura enfocou as dificuldades conceituais e delimitadoras do construto bem como a abordagem da gestão na atuação do profissional de Secretariado. A pesquisa de campo possibilitou o atendimento do objetivo proposto bem como respondeu à questão de pesquisa suscitada no início do trabalho.

Verificou-se forte predominância das teorias de gestão nas respostas obtidas junto aos discentes abordados. Percebe-se que, entre os discentes da amostra participante, há compreensão diversificada acerca da gestão secretarial, porém com uma clara tendência para conceitos de gestão, sejam eles relacionados diretamente às atividades secretariais, seja de forma generalista. É fato que os discentes têm conhecimento acerca do tema, mesmo com ausência de uniformidade nas respostas. Tal ausência é plenamente pautada na diacronia do construto.

A Gestão Secretarial é um construto em desenvolvimento, e, embora se tenha popularizado e até mesmo se institucionalizado como conteúdo específico, carece de estudos que o aprofundem. Identificar a visão dos atores sociais que a envolvem é imperativo para sua demarcação conceitual, pois alia teoria e empirismo. Neste sentido, a presente pesquisa contribuiu por revelar a percepção de um público significativo para a construção científica do Secretariado.

Verificou-se, também, que as respostas dos participantes alinham-se ao que é 
predito na literatura sob dois aspectos: primeiro, por esboçar ausência de um conceito específico; segundo, por associar as teorias de gestão ao construto da Gestão Secretarial. Sendo o segundo aspecto, o de maior relevância para os achados desta pesquisa. Tal associação revela concordância dos discentes ao que proposto pela literatura como novo perfil para os secretários, bem como ao que acenado como possibilidade conceitual para a gestão secretarial.

Infere-se, portanto, que, para a amostra pesquisada, as teorias de gestão estão intrinsecamente relacionadas à Gestão Secretarial, o que, por si só, pode não ser o maior legado deste estudo, mas, ao se verificar a variedade de teorias citadas, confirma-se também a ausência de fronteiras para o construto ora abordado. A pluralidade da gestão secretarial impõe aos pesquisadores, estudantes e profissionais da área, um olhar crítico sobre o tema para que se encontre o equilíbrio daquilo que reflete a identidade secretarial. Acredita-se que essa ausência de limites é natural e própria do processo de transformação e amadurecimento de teorias em construção.

A pesquisa avança nos estudos acerca do tema, pois discute sua essência conceitual e identitária, desvinculando-se da prática observada comumente de relacionar assuntos emergentes ao construto. Ademais, buscou-se uma aproximação delimitatória por meio da contribuição empírica, antes não observada.

Os resultados apresentados não podem ser generalizados, pois representam o pensamento da amostra abordada e, portanto, estudos adicionais precisam ser desenvolvidos envolvendo outras amostras de discentes de outras instituições de ensino, de profissionais, gestores, pesquisadores e todos aqueles que, de alguma forma, poderão somar para o desenvolvimento do saber na área de Secretariado Executivo. Desta forma, será possível a continuidade de uma possível proposta demarcatória do construto e a confirmação do sentido de complementaridade da pesquisa científica.

\section{WHAT IS UNDERSTOOD BY SECRETARIAL MANAGEMENT: THE COMPREHENSION OF A SAMPLE OF EXECUTIVE SECRETARIAT STUDENTS}

\section{ABSTRACT}

The Secretarial Management is a recurrent theme, although its delimitation still lacks studies which prove it as construct. The aim of this article is to analyze the comprehension of Executive Secretariat students from the Federal University of Ceará (UFC) about Secretarial Management. In order to accomplish that, a literature review is performed followed by a field research with students that are regulary enrolled in the Secretariat Techniques II discipline of the Executive Secretariat course of UFC. 53 undergraduate students participated during the years 2014 and 2015. The study is a descriptive and exploratory research with a qualitative nature whose data were analysed by means of content analysis. This allowed to infer that, among the Executive Secretariat students from UFC, there exist distinct comprehensions about secretarial management, although with a clear tendency to the theories of management that are directly related to the secretarial activities or in a more general way. It was observed that some of the answers relate the subject to administrative activities and not, specifically, to secretarial practices.

Keywords: Secretarial Management. Perception. Secretariat Students.

\section{REFERÊNCIAS}

AKPOMI, M.; ORDU, P. Modern office technology and the secretary's productivity in private business organisations. African Journal of Business Management, South Africa, v. 3, n. 8, p. 333-339, ago. 2009. Disponível em: $<$ http://www.academicjournals.org/journal/ AJBM/article-full-text-pdf/1EA0B3517153>. Acesso em: 26 jul. 2016. 
BARDIN, L. Análise de conteúdo. Lisboa: Edições 70, 2002.

BARROS, C. M. P.; BRAGA, M. C.; SILVA. J. S. As competências gerenciais na atuação do secretário executivo no nível estratégico. Expectativa, Toledo, v. 10, n. 10, p. 91-106, 2011. Disponível em: $<$ http://e-revista.unioeste.br/index.php/expectativa/article/view/6096>. Acesso em: 26 jun. 2015.

BARROS, C. M. P. et al. As competências gerenciais desenvolvidas pelos secretários executivos. GeSec, São Paulo, v. 4, n. 2, p. 25-47, jul./dez. 2013. Disponível em: <http://www. revistagesec.org.br/ojs-2.4.5/index.php/secretariado/article/view/131

/pdf_1\#.VMnjs9LF9A0>. Acesso em: 26 jun. 2015.

BARROS, C. M. P.; SILVA, J. S.; FERREIRA, F. D. Gestão secretarial: delineando atividades, funções e competências gerenciais. Revista de Gestão e Contabilidade da UFPI, Floriano, v. 2, n. 2, p. 149-171, 2015. Disponível em: $<$ http://www.ojs.ufpi.br/index.

php/gecont>. Acesso em: 13 fev. 2016.

BECKER, G.; CEOLIN, J. Gestão secretarial: uma nova visão de assessoramento nas organizações. Secretariado Executivo em Revist@, Passo Fundo, v. 6, 2010. Disponível em: <http://www.upf.br/seer/index.php/ ser/article/view/2100/1316>. Acesso em: 26 jun. 2015.

BEUREN, I. M (Org.). Como elaborar trabalhos monográficos em contabilidade: teoria e prática. 3. ed. São Paulo: Atlas, 2008.

BÍSCOLI, F. R. V.; CIELO, I. D. Gestão organizacional e o papel do secretário executivo. Expectativa, Toledo, v. 3, n. 3, p. 11-19, 2004. Disponível em: <http://e-revista.unioeste.br/index.php/expectativa/article/viewFile/741/626>. Acesso em: 3 jul. 2015.
BORTOLOTTO, M. F. P.; WILlERS, E. M. Profissional de Secretariado Executivo: explanação das principais características que compõem o perfil. Expectativa, Toledo, v. 4, n. 4, p. 45-56, 2005. Disponível em: <http://e-revista.unioeste.br/index.php/expectativa /article/viewFile/410/326>. Acesso em: 28 jun. 2015.

BRASIL. Instituto Nacional de Estudos e Pesquisas Educacionais Anísio Teixeira. Portaria n 210 de 22 de junho de 2012. Diário Oficial da União, Brasília, DF, 25 jun. 2011. Seção 1, pág. 17-18.

BRASIL. Lei $\mathrm{N}^{0} 7377$, de 30/09/85, complementada pela Lei No. 9261, de 10/01/96. Dispõe sobre o exercício da profissão de secretário e dá outras providências. Federação Nacional das Secretárias e Secretários, Curitiba, 1985. Disponivel em: <http://www.fenassec .com.br>. Acesso em: 25 jul. 2016.

BRASIL. Ministério da Educação. Resolução $\mathrm{n}^{\mathrm{o}}$ 03, de 23 de junho de 2005. Institui as Diretrizes Curriculares Nacionais para o curso de graduação em Secretariado Executivo e dá outras providências. Diário Oficial da União, Brasília, DF, 27 jun. 2005. Seção 1, p. 79. Disponível em: <http://portal.mec.gov.br/cne/arquivos/pdf/rces003_05.pdf $>$. Acesso em: 24 jun. 2015.

BRÜNE, S.; GONTARECK, M. Secretariado Executivo: uma nova perspectiva acerca do atendimento ao cliente e sua qualidade intrínseca. In: III ENCONTRO NACIONAL ACADÊMICO DE SECRETARIADO EXECUTIVO (III ENASEC), 3., 2013, João Pessoa. Anais... João Pessoa: UFPB, 2013. 1 CD-ROM.

DIAS, S.; CARDOSO, A. C. Secretário gestor: a força administrativa. In: SEMINÁRIO MULTIPROFISSIONAL INTEGRADO DE SECRETARIADO DA REGIÃO NORDESTE, 11., 2011, Recife. Anais... Recife: Sinsepe, 2011. 1 CD-ROM. 
EDDY, E. N.; AKPAN, E. E. Statistical relationship between the performance of students in shorthand and typing: case study of Akwa Ibom State Polytechnic, Ikot Ekpene, Nigeria. Educational Research and Review, Netherlands, v. 2, n. 12, p. 321-324, Dec. 2007. Disponível em: <http://www. academicjournals.org/journal/ERR/article-full-text-pdf/2CC98B43922>. Acesso em: 25 jul. 2016.

GODOI, C. K.; BALSINI, C. P. V. A pesquisa qualitativa nos estudos organizacionais brasileiros: uma análise bibliométrica. In: GODOI, C. K.; BANDEIRA-DE-MELLO, R.; SILVA, A. B. Pesquisa qualitativa em estudos organizacionais: paradigmas, estratégias e métodos. 2. ed. São Paulo: Saraiva, 2010.

GRANDO, C.; CORREA, S. A. G.; RINALDI, N. R. O perfil do Secretário Executivo frente às necessidades das instituições financeiras. Expectativa, Toledo, v. 6, n. 6, p. 9-64, 2007. Disponível em: <http://e-revista.unioeste.br/ index.php/expectativa/issue/view/171/showToc $>$. Acesso em: 28 jun. 2015.

GUARIDO FILHO, E. R. ; MACHADO-DA-SILVA, C. L.; GONÇALVES, S. A. Institucionalização da teoria institucional no contexto dos estudos organizacionais no Brasil. In: ENCONTRO DA ANPAD, 33., 2009, São Paulo. Anais... São Paulo: Anpad, 2009. 1 CD-ROM.

GUIZZO, B. S.; KRZIMINSKI, C.O.; OLIVEIRA, L.L.C. O software QSR NVIVO 2.0 na análise qualitativa para a pesquisa em ciências humanas e da saúde. Rev. Gaúcha de Enfermagem, Porto Alegre, v. 24, n. 1, p. 5360, 2003. Disponível em: <www.seer.ufrgs.br/ RevistaGauchadeEnfermagem/article/download/4437/2363>. Acesso em: 20 jul. 2016.

HALICI, A.; YILMAZ, B.; KASIMOĞLU, M. Employment Predictions in Secretarial Occupation. Journal of Management and Sustainability, Toronto, v. 2, n. 2, p. 187-196, 2012. Disponível em: <http:/www.ccsenet.org/journal/index.php/ jms/article/view/18181>. Acesso em: 26 jul. 2016.
KELLE, U. Análise com auxílio de computador: codificação e indexação. In: BAUER, $M$. W.; GASKELL, G. (Org). Pesquisa qualitativa com texto, imagem e som: um manual prático. Petrópolis: Vozes, 2002, p. 393-415.

LASTA, A.; DURANTE, D. G. A gestão secretarial no cenário organizacional contemporâneo. Secretariado em Revista, Rio Grande do Sul, v. 4, 2008. Disponível em: <http://www. upf.br/seer/index.php/ser/article/view/1768>. Acesso em: 2 jul. 2015.

LOTTE, R. I. A atuação do Secretário Executivo no Oeste do Paraná numa economia baseada no agronegócio. Expectativa, Toledo, v. 4, n. 4, p. 57-64, 2005. Disponível em: <file://C:/ Documents $\% 20$ and $\% 20$ Settings/Administrador/Meus\%20documentos/Downloads/ 411-1388-1-PB.pdf $>$. Acesso em: 28 jun. 2015.

MACHADO, F. F. Gestão de carreira. In: PORTELA, K. C. A.; SCHUMACHER, A. J. Gestão Secretarial: o desafio da visão holística. Cuiabá: Adeptus, 2009.

MOREIRA, K. D. et al. As competências contemporâneas do secretário executivo e a relação com as competências do middle manager. Revista de Gestão e Secretariado - GeSec, São Paulo, v. 7, n. 1, p. 45-66, jan./abr. 2016. Disponível em: <https://www.revistagesec.org.br /secretariado/article/view/400/pdf $>$. Acesso em: 25 jul. 2016.

MOURA, M. A. Trabalho e competências em transformação: o papel do profissional de Secretariado. Expectativa, Toledo, v. 7, n. 7, p. 27-49, 2008. Disponível em: <file:///C:/Documents $\% 20$ and $\% 20$ Settings/Administrador/Meus\%20documentos/Downloads/2854-10383-1-PB.pdf $>$. Acesso em: 28 jun. 2015.

NONATO JÚNIOR, R. Epistemologia e teoria do conhecimento em Secretariado Executivo: a fundação das ciências da assessoria. Fortaleza: Expressão Gráfica, 2009. 
Objeto de pesquisa em Secretariado Executivo. In: DURANTE, D. G. Pesquisa em Secretariado: cenários, perspectivas e desafios. Passo Fundo: UPF, 2012.

RESTIER, I. A tecnologia da Informação como patrimônio empresarial. In: D'ELIA, Bete; AMORIM, Magali; SITA, Maurício. Excelência no Secretariado. São Paulo: Ser Mais, 2013.

RIBEIRO, N. L. A. Secretariado: do escriba ao gestor. 2. ed. São Luis: [s.n.], 2005.

RIZZI, M. Valiosos profissionais: secretárias, secretários e assessores, valorização da profissão e participação nos resultados empresariais. In: AMORIM, M. Excelência no Secretariado. São Paulo: Ser Mais, 2013.

ROBERTS, R. D. et al. Inteligência emocional: um construto científico? Paidéia, Ribeirão Preto, v. 12, n. 23, p. 77-92, 2002. Disponível em: $<$ http://www.scielo.br/pdf/paideia/v12n23/06. pdf $>$. Acesso em: 3 jul. 2015.

SABINO, R. F.; ROCHA, R. F. Secretariado: do escriba ao web writer. Rio de Janeiro: Brasport, 2004.

SCHMIDT, C. M. et al. Perfil empreendedor: um estudo com acadêmicos de Administração e Secretariado Executivo. Expectativa, Toledo, v. 7, n. 7, p. 51-64, 2008. Disponível em: <file://C:/Documents\%20and\%20Settings/ Administrador/Meus\%20documentos/Downloads/2857-10382-1-PB.pdf>. Acesso em: 28 jun. 2015.

SILVA, A. C. A atuação do Secretariado Executivo na gestão da Informação e do conhecimento. In: D'ELIA, Bete; AMORIM, Magali; SITA, Maurício. Excelência no Secretariado. São Paulo: Ser Mais, 2013.
SILVA, A. C. B. R. Atuação e competências do secretário executivo: Assessor, Gestor, Consultor, Empreendedor. In: ENCONTRO NACIONAL ACADÊMICO DE SECRETARIADO EXECUTIVO, 1., 2010, Toleto. Anais... Toleto: UNIOESTE, 2010. 1 CD-ROM.

SILVA, J. S.; BARROS, C. M. P.; BARBOSA, M. F. S. Fundamentação da gestão secretarial: um estudo bibliométrico. GeSec, São Paulo, v. 3, n. 2, p 106-126, jul./dez. 2012. Disponível em: $\quad<\mathrm{http}$ ://www.revistagesec.org.br/secretariado/article/view/114\#.Vwp0AZwrJdg>. Acesso em: 3 jul. 2015.

SILVA, N. S. A. C. O gestor secretarial alavancando projetos. In: ENCONTRO NACIONAL ACADÊMICO DE SECRETARIADO EXECUTIVO (II ENASEC), 2., 2011, Passo Fundo. Anais... Passo Fundo: UPF, 2011. 1 CD-ROM.

TRIOLA, M. F. Introdução à estatística. 10. ed. Rio de Janeiro: LTC, 2012. 